انتخابيذيرى ذرات رسوب در اثر فرسايش شيارى در خاكهاى با بافت مختلف

\author{
نسرين صادقيان* و عليرضا واعظى'

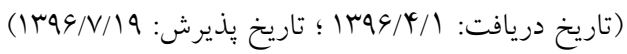

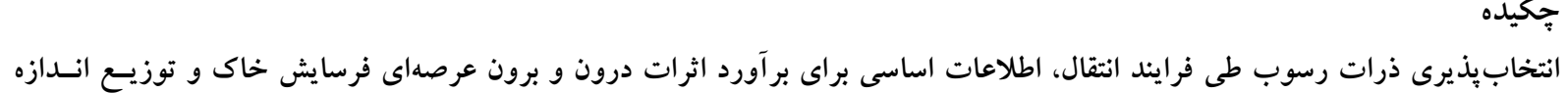

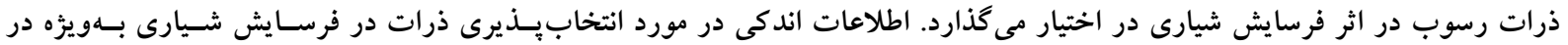

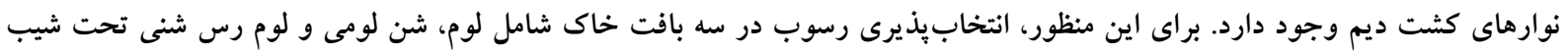

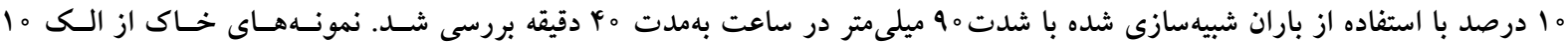

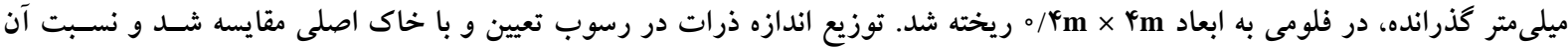

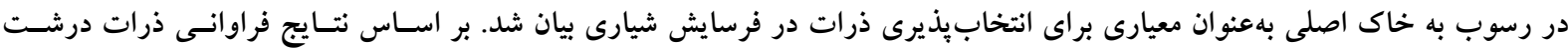

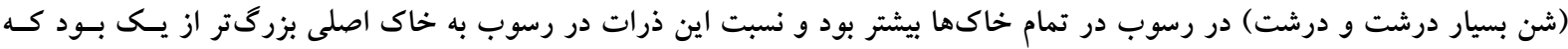

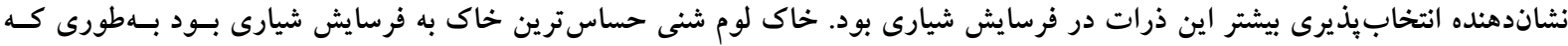

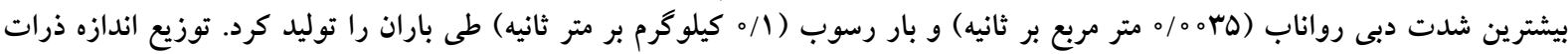

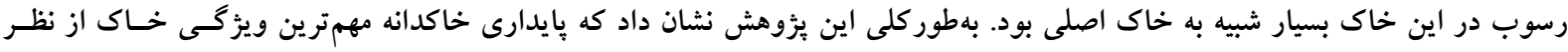

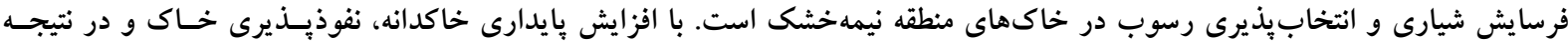
تنش برشى جريان در شيارها كاهش مي يابد.

وازههاى كليدى: اندازه خاكدانه، بار بستر، توزيع اندازه ذره، قدرت جريان، غلتيدن 


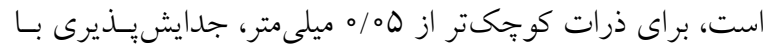

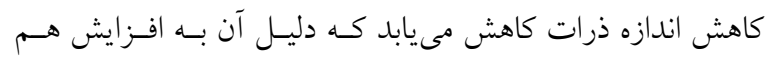

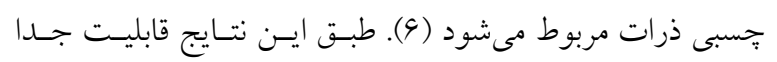

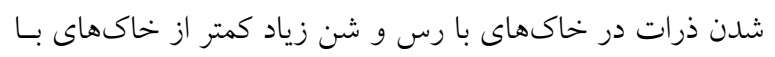

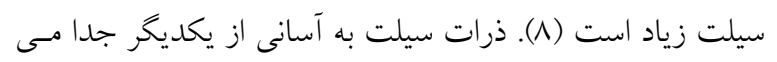

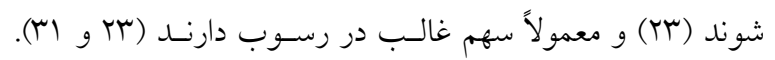

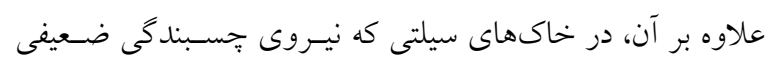

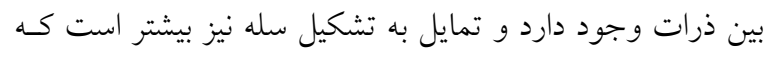

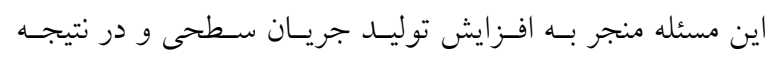

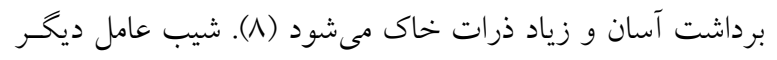

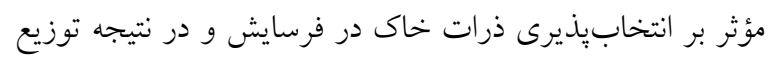
اندازه ذرات رسوب است. در شيبهاى تند، ذرات درشت بهديليل

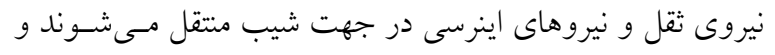

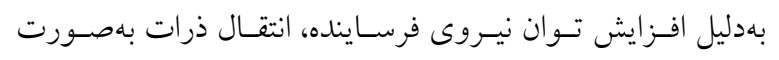

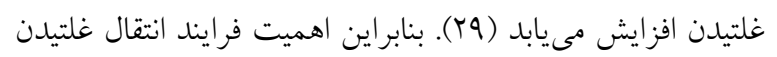

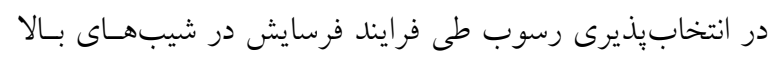

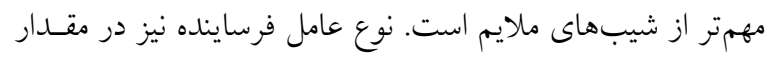

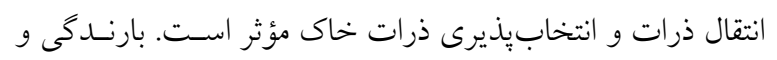

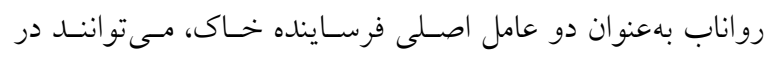

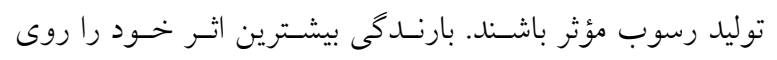

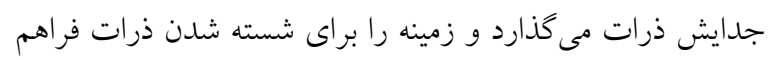

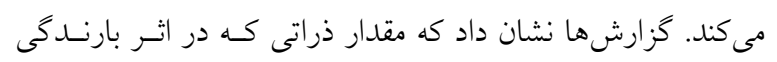

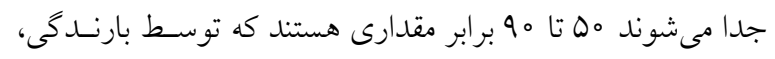

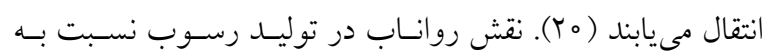

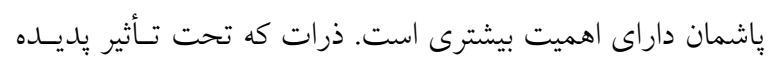

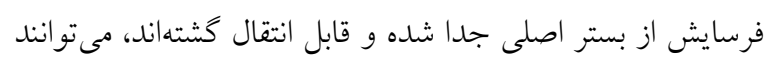
توسط جريان آب به شكل بار معلق و بار بستر انتقال بيدا كنند.

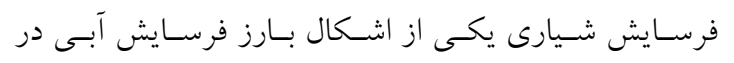

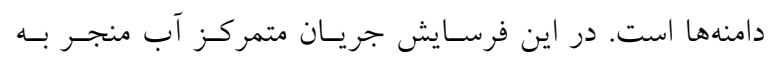
برداشت ذرات در مسير و ايجاد كانالهاى باريك در امتداد شيار

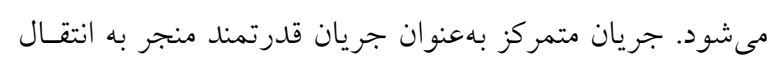

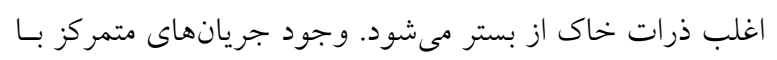

مقدمه فرسايش خاى بـهوسـيله آب عامـل اصسلى تخريسب خـاك در

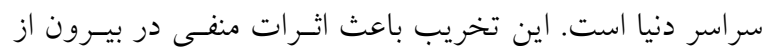

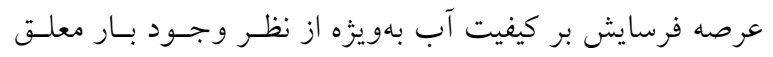

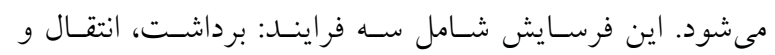

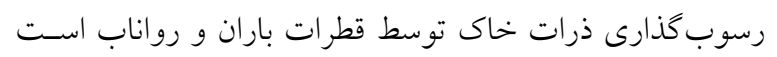

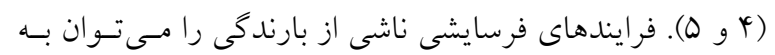

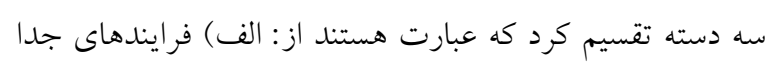

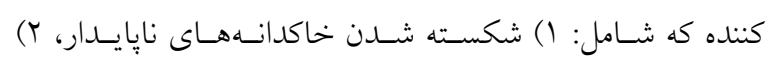

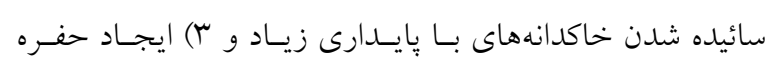

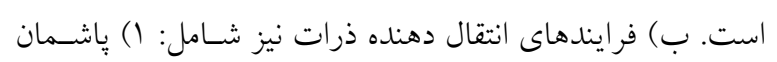

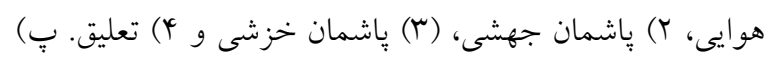

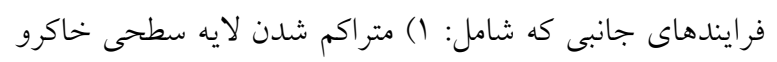

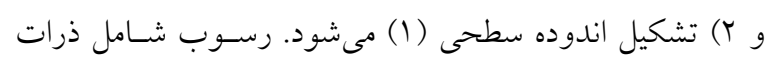

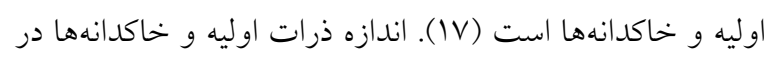

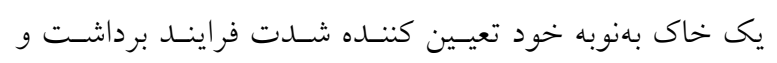

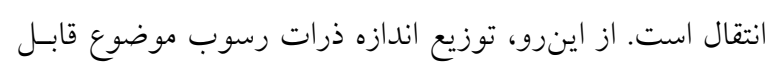

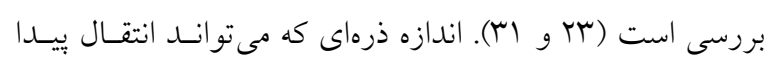

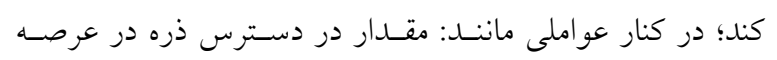
فرسايشى، امكان توليد ذره در طى بِديده فرسايش و انتخابى يـا

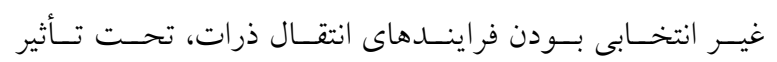

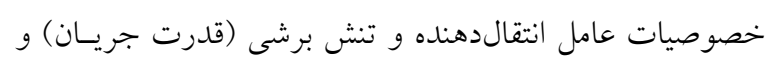

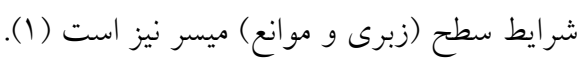

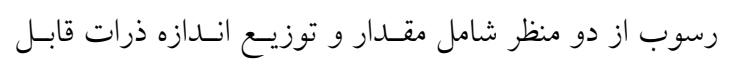
بررسى است. آزمايشات نشان مىدهد كه در شرايط بايدار، توزيع

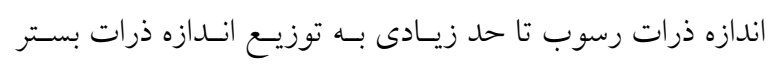

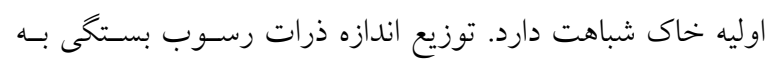

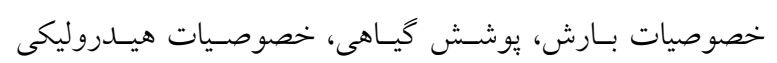

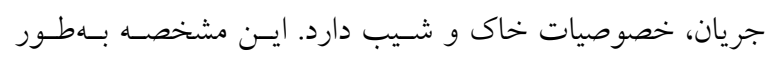

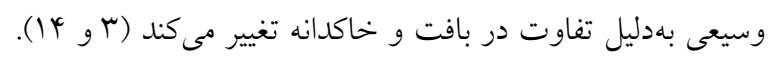

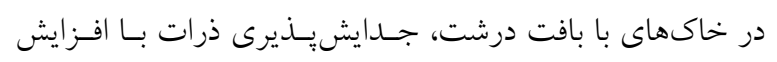

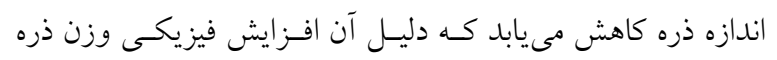


مى توان به تأثير فرسايش بر كيفيت خاك و بـارورى آن (اثـرات

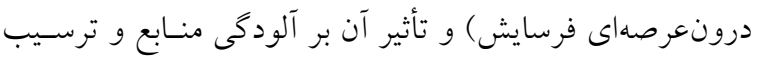
بر سطح اراضى (اثرات برونعرصسهاى فرسـايش) اشـاره كـرد.

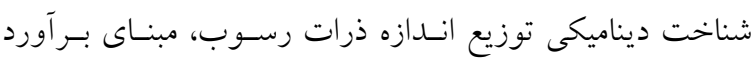

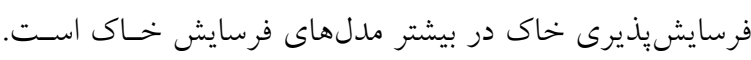

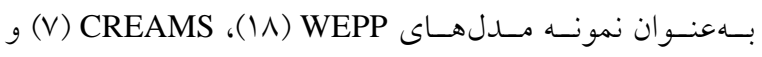
بـ (19) GUST

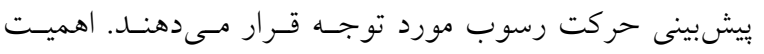

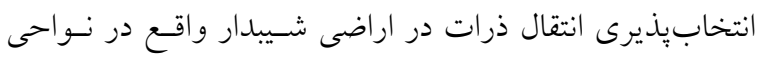

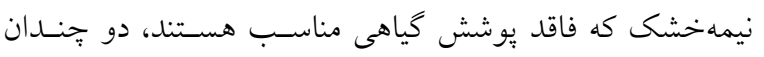

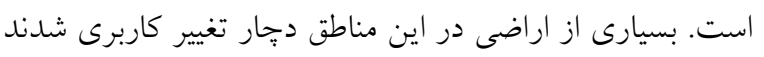

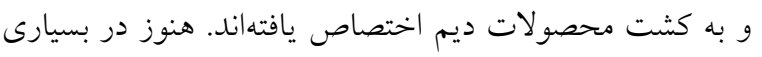
از كشتزارهاى ديـم، شـخم و كشـت بـهـ مـوازات شـيب انجـام

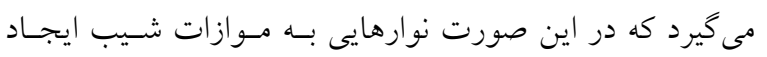

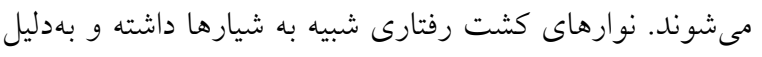

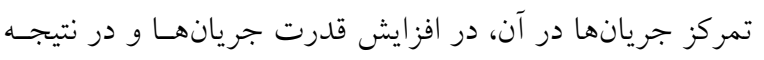

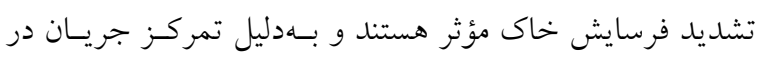

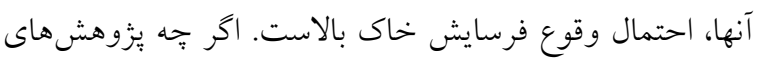

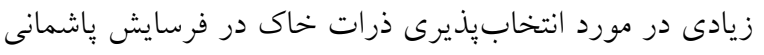

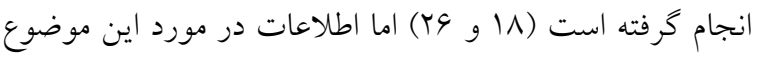

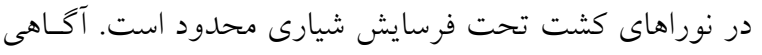
از مقدار و توزيع اندازه ذرات رسـوب حاصـل از ازيسن شـيارها

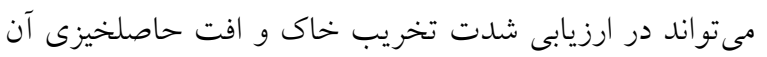

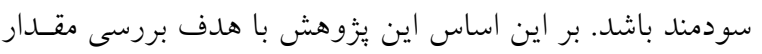

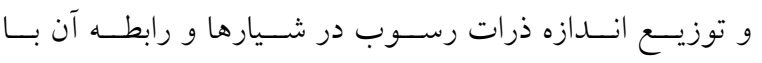

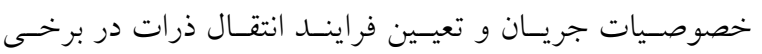
خاكهاى ديم منطقه نيمه خشك انجام كرفت.

\section{مواد و روشها - - ماد} نمونهبرداى خاك و تعيين ويزگگ هاى آن

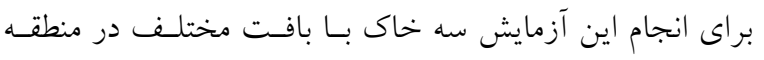

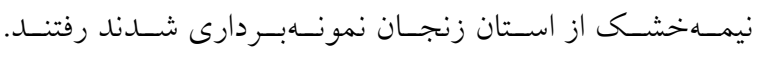

تنش برشى بيشتر از مقدار آستانه تـنش برشى بحرانسى باعـث

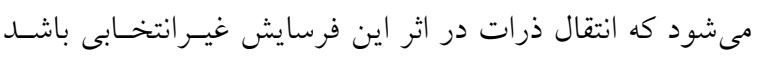

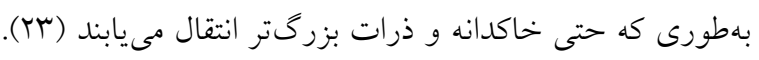
اختلاف بزركى در اندازه ذرات رسوب (شامل خاكدانه و ذرات

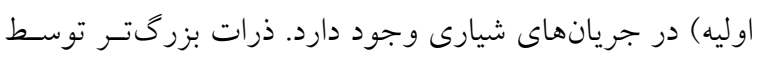
جريان شيارى نسبت به جريان بينشيارى منتقل مىشوند كه اين

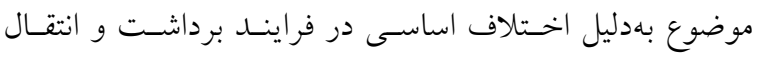
است. در فرايند فرسايش شيارى نسبت به فرسايش بينشسيارى،

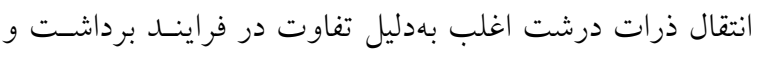

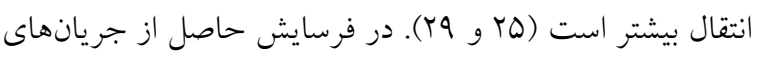

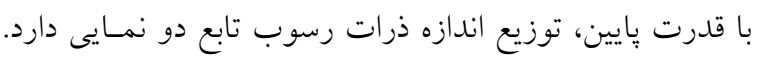

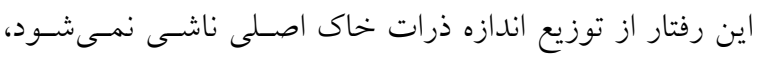

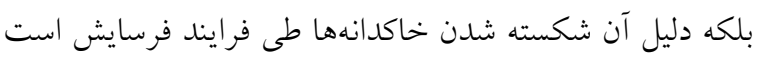

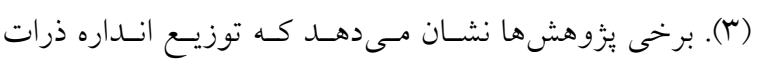

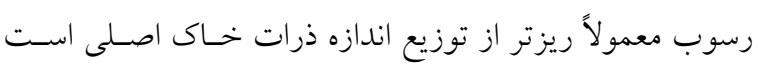

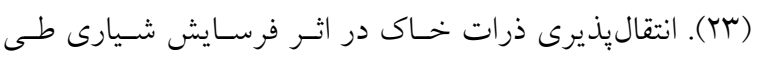

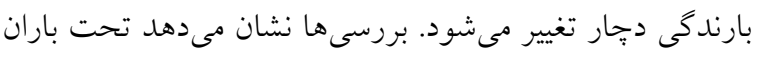

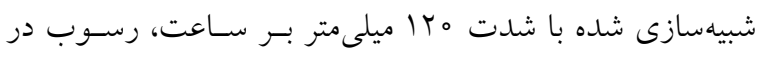

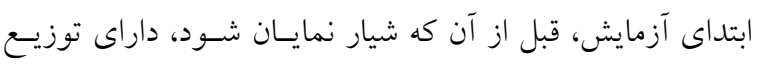

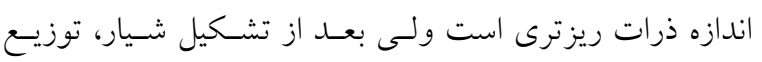

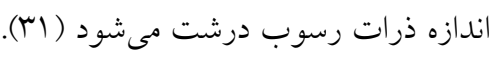

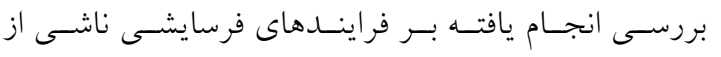

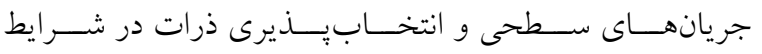

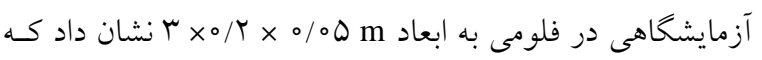

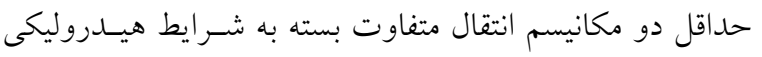

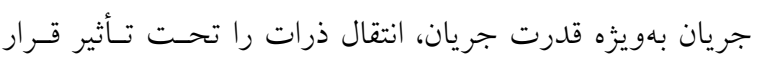

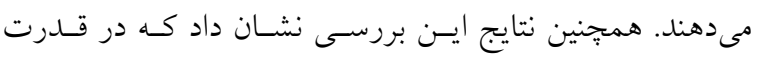

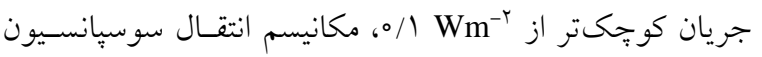

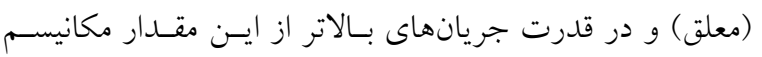
غلتيدن فعال است (r).

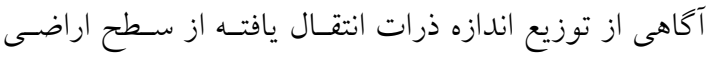

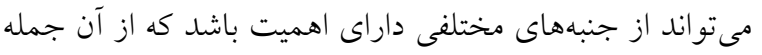


در داخل فلوم بـر اسـاس جـرم مخصـوص ظـاهرى خـاكهـا

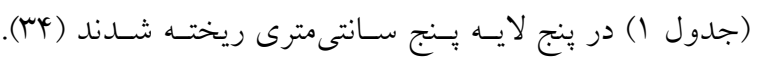

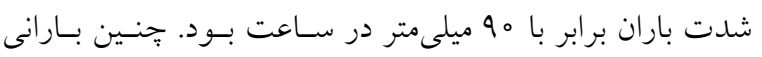

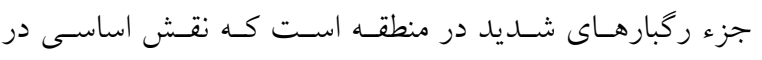

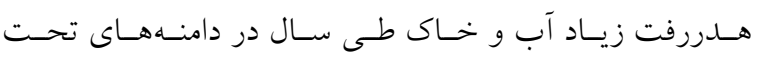

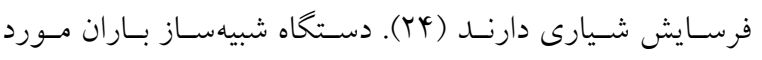

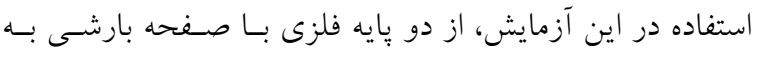

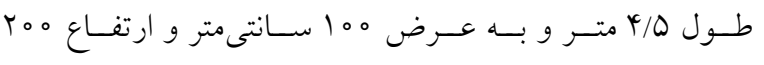

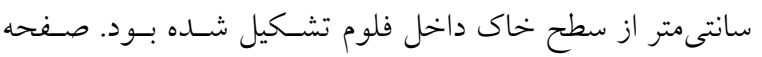
بارش شامل هب قطعه نازل اسبرى جت و ساخت كشور آمريكا

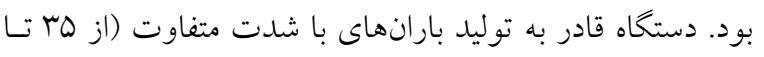

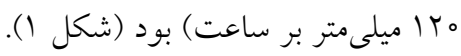

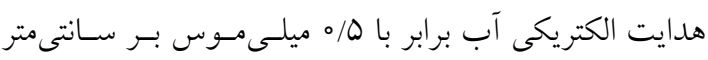

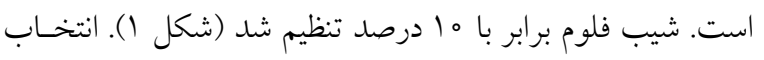

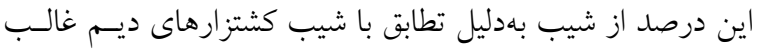

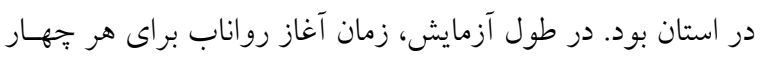

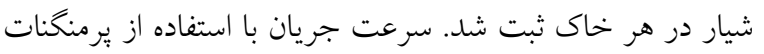

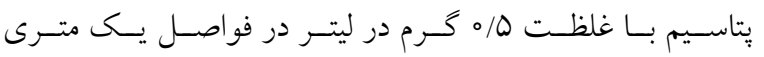

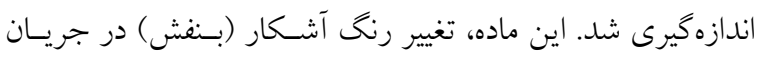

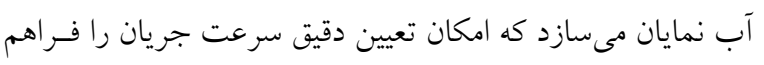

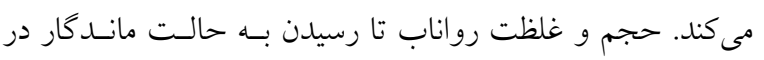

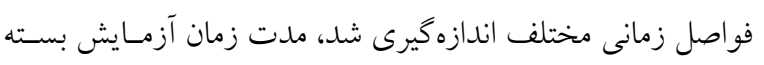

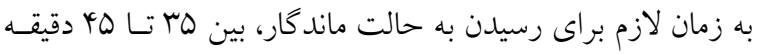

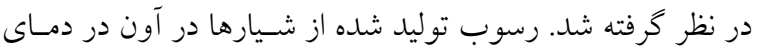

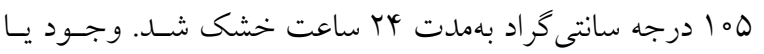

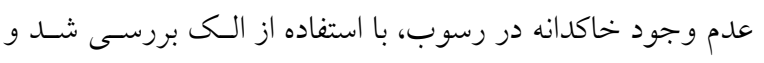

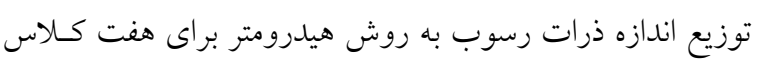
اندازه ذرات تعيين شد.

\section{تجزيه وتحليل دادهها}

آزمايشات مربوط به توزيع اندازه رسوب درئ در قالب طـرح كـاملاً

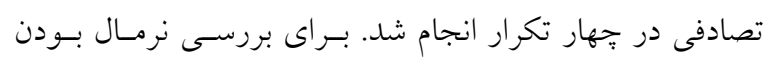

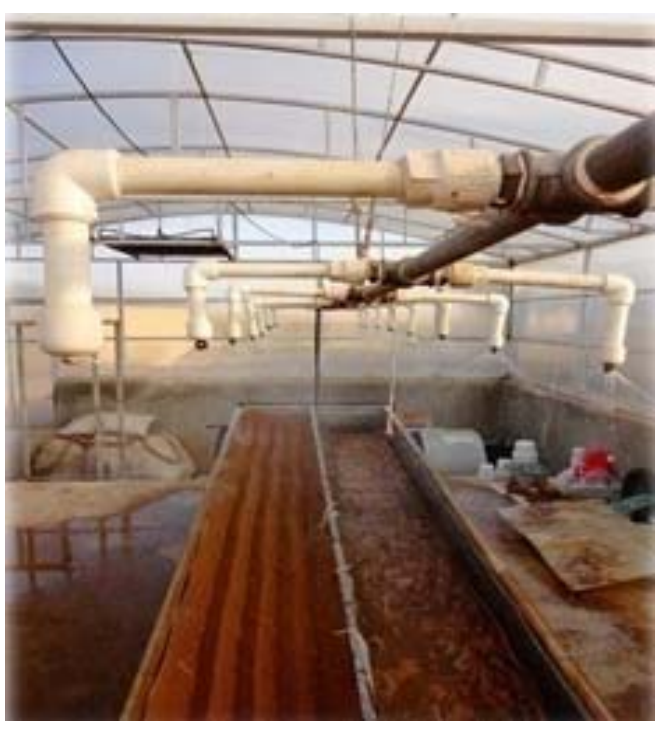

شكل ا. نمايى از فلوم مورد استفاده در آزمايش

خاكىها از كشتزارهاى ديم از عمق •Y - ـ سـانتىمترى نمونسه

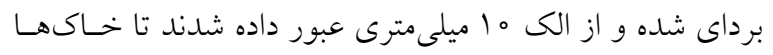

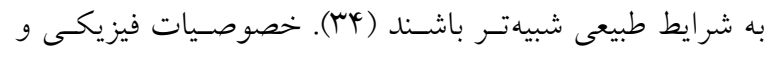

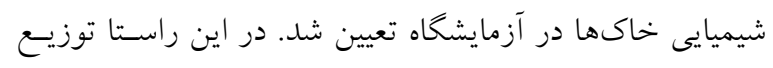
اندازه ذرات به روش هيدرومتر (11)، جرم مخصسوص ظـاهرى

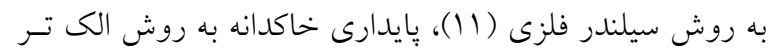

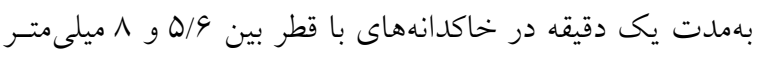

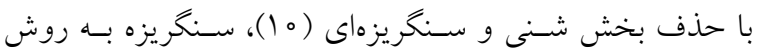

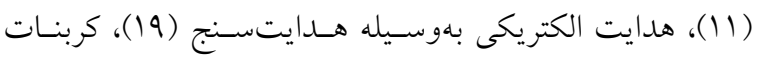

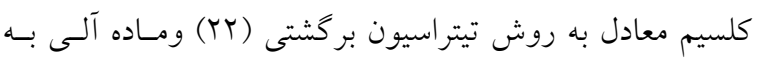

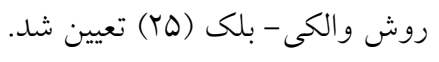

تعيين توزيع اندازه ذرات در اثر فرسايش شيارى

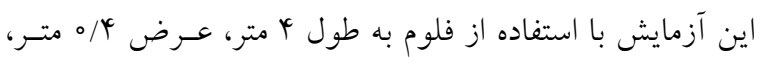

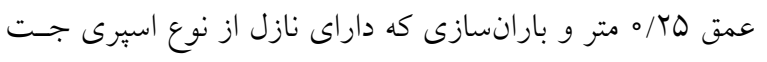
كه به فاصله دو متر از سطح خاك فلـوم فاصسله داشـت، انجـام

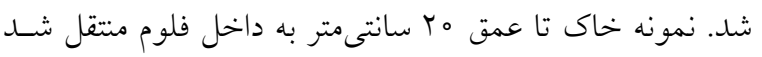

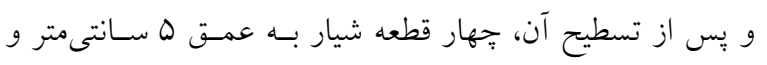
فاصله ما سانتى مترى به مقطع مثلثى شكل ايجاد شد. خـاكهـا 


\begin{tabular}{|c|c|c|c|c|}
\hline \multicolumn{5}{|c|}{ جدول ا. ويزگى هاى فيزيكى و شيميايى خاكهاى مورد مطالعه } \\
\hline ل ل ل ام رس شنى & 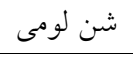 & 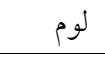 & واحد & خصوصيات خاك \\
\hline$\Delta / \Gamma \Delta$ & $\circ / 94$ & $\circ / 0$ & $(\%)$ & شن بسيار درشت \\
\hline$r r / 90$ & $\mathrm{~V} / \mathrm{r}^{4}$ & $1 / 94$ & $(\%)$ & شن اشت \\
\hline rT/NT & $\mid V / \Lambda \Lambda$ & T/GY & $(\%)$ & 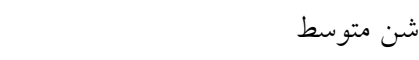 \\
\hline IT/VQ & $r 9 / 10$ & Q/N & $(\%)$ & 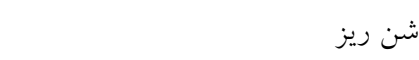 \\
\hline T/VQ & rY/QV & $r \mid r$ & $(\%)$ & 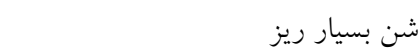 \\
\hline$r r / 0_{0}$ & IV/ar & re/A。 & $(\%)$ & 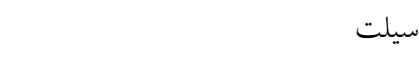 \\
\hline$r r / \Delta \circ$ & V/Qr & $\mid V / 4 \Lambda$ & $(\%)$ & 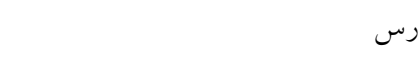 \\
\hline$r \mid / \Lambda$ & $r / \%$ & $10 / 90$ & $(\%)$ & سنكريزه \\
\hline $1 / \circ V$ & $0 / 94$ & $\circ / 9 V$ & $(\mathrm{~mm})$ & ميانخين وزنى قطر خاكدانههاى بايدار \\
\hline $1 / 4 \circ$ & $1 / 79$ & $1 / T_{0}$ & $\mathrm{~g} \mathrm{~cm}^{-r}$ & جرم مخصوص ظاهرى \\
\hline r/ar & $r / \Delta)$ & T/TG & $\mathrm{g} \mathrm{cm}^{-r}$ & جرم مخصوص حقيقى \\
\hline$\circ / \Delta \Lambda$ & $1 / \pi 4$ &.$/ 99$ & $(\%)$ & 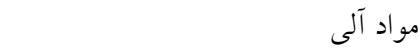 \\
\hline$r / \mu_{\Lambda}$ & $r / \Lambda \circ$ & T/NQ & $(\%)$ & درصد سديم تبادلى \\
\hline ro/०。 & $r Q / \Lambda T^{2}$ & $r V / \circ \circ$ & $(\%)$ & كربنات كلسيم معادل \\
\hline
\end{tabular}

تغييرات رس در خاكها، مىتوان كفـت كـه ذرات رس نقشى

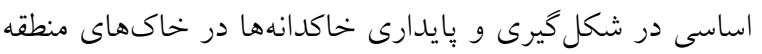

$$
\text { مورد بررسى دارد. }
$$

شكل (Y) تغييرات زمان آغاز روانـاب، دبسى جريـان و بــار

رسوب در خاكهاى مورد بررسى را نشان مىدهد. نتايج نشـان رمان

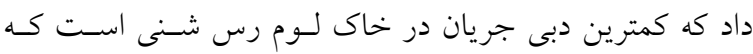

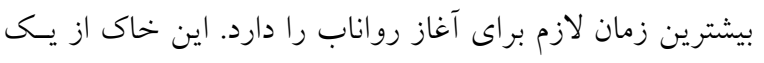

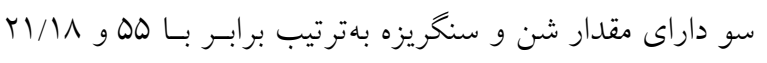

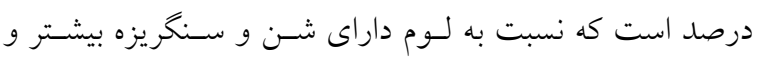

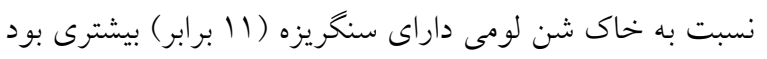

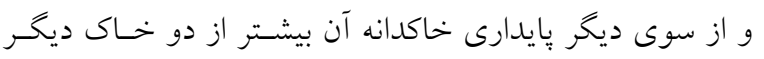

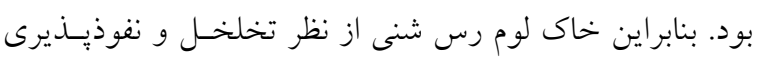

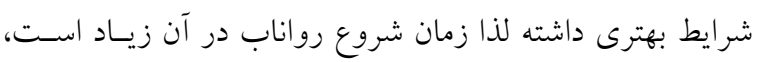

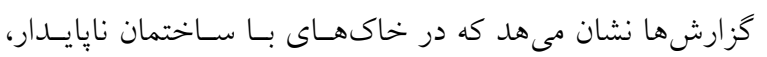

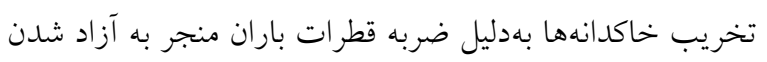
ذرات ريز مىشود كه اين ذرات به عمق خاك حركـت كـرده و

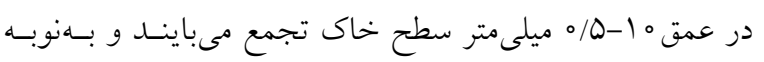

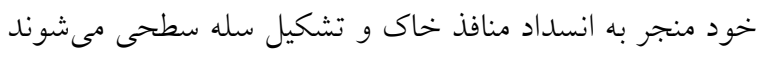

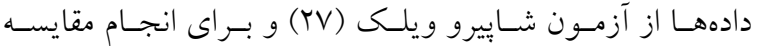

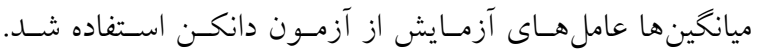

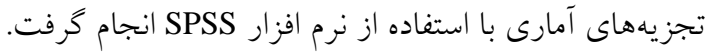

\section{نتايج و بحث} مطابق جدول (1) در خاكهـاى مـورد بررسى دامنسه تغييـرات

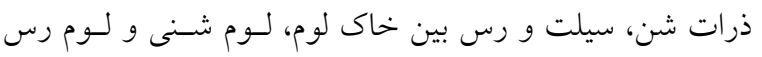

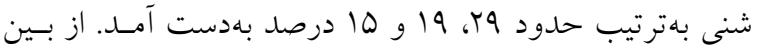
اجزاى شن در خاك، بيشترين تفاوت بين خاكها از نظـر ذرات شن بسيار درشت، درشت و متوسط بود (جدول ()). مقدار ماده

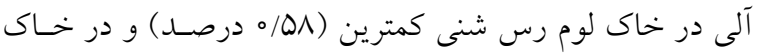

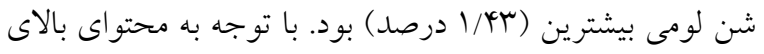

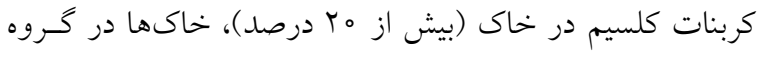

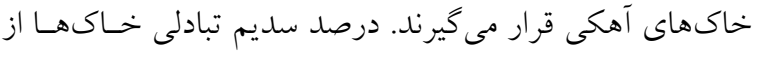
V/Or

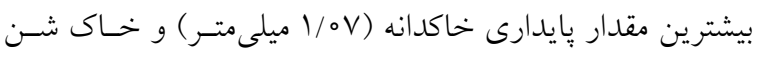

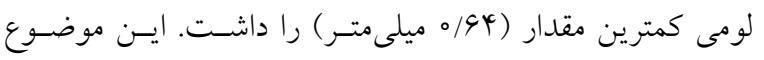

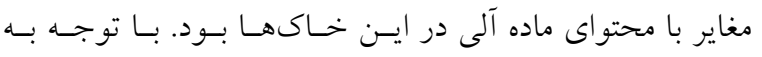




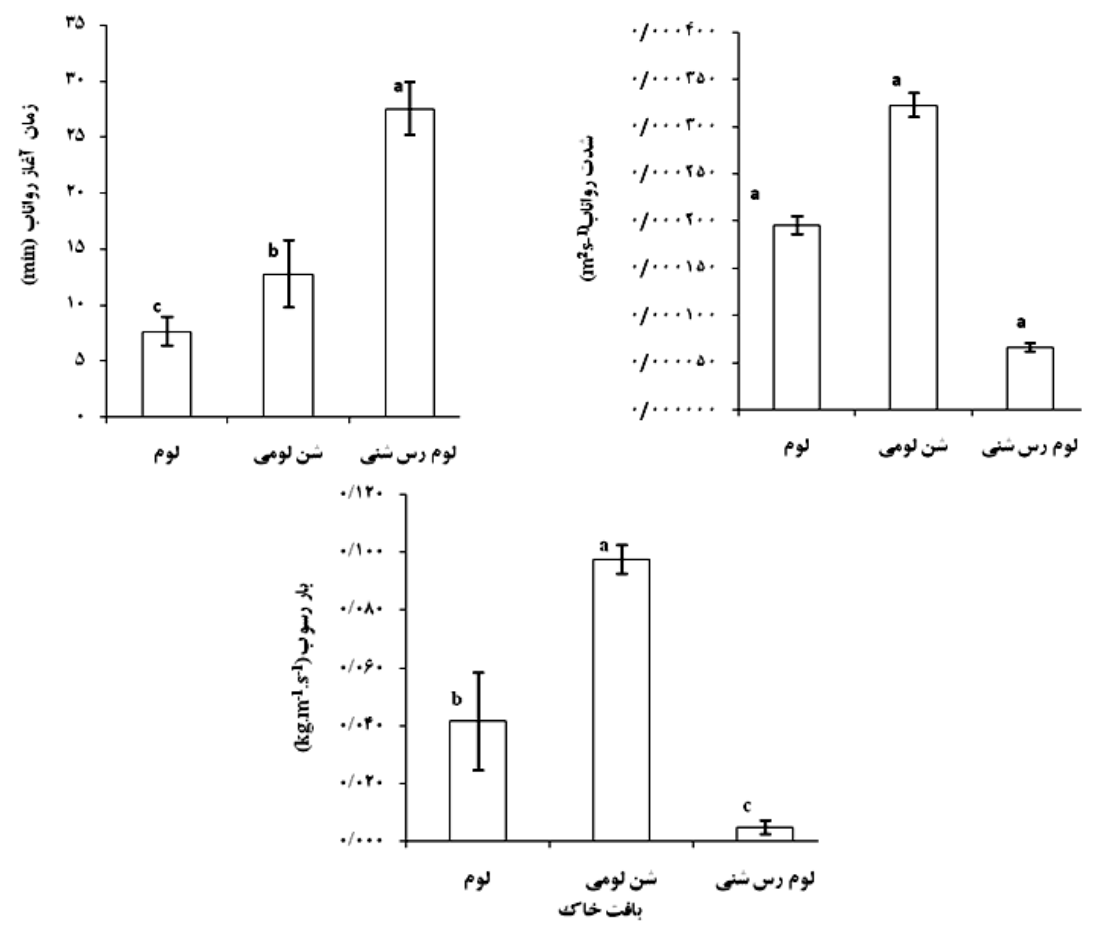

شكل r. تغييرات زمان آغاز رواناب، دبى جريان و بار رسوب در خاكهاى مورد بررسى. حروف مشابه داراى اختلاف

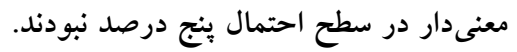

لومى، وزن ذرات انتقال يافته نيز بزرگ است. بزرگى بـار رسوب

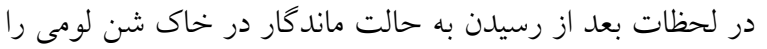

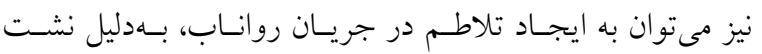

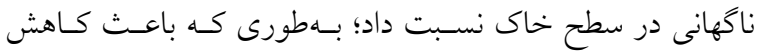

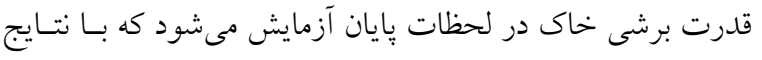

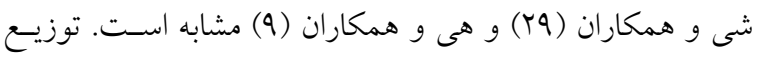

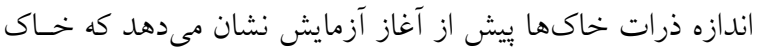

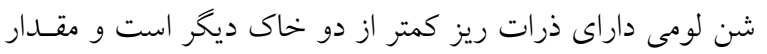

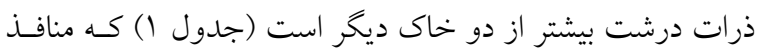

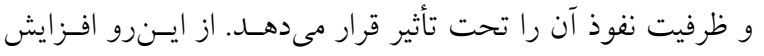
رواناب در آن به كندى صورت مى گيرد و ديرتر از دو خاك ديخر

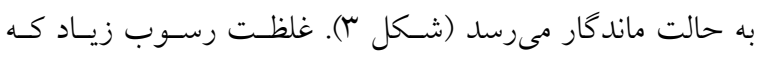

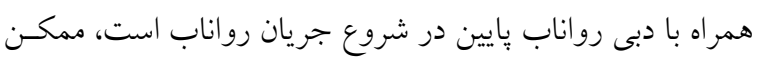

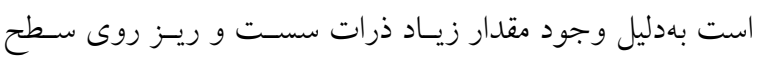

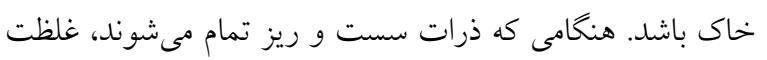

(Y I ). برخلاف برخى كزارشها كه در آن وجود ذرات ريز اوليه بيشتر (سيلت و رس) خاك را مستعد تشكيل سله كرده، توليـد

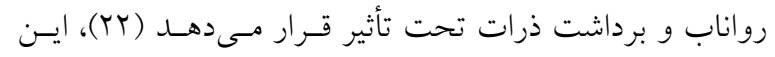

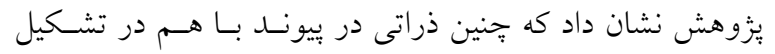

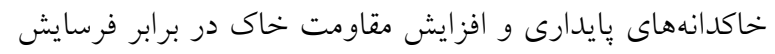
شيارى مؤثر هستند. (شكل r) نيز نشان مى هده، كه كمترين ميزان دبى روانساب و

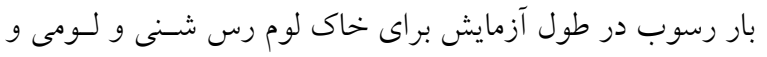

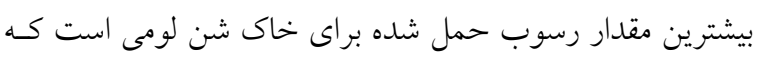

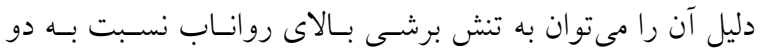

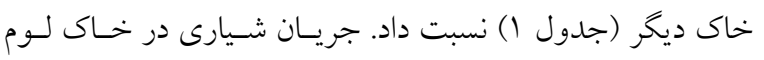

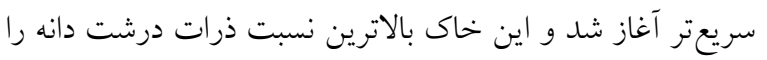
در رسوب ظاهر كرد. همجينين بِايـدارى خاكدانسه در ايـن خـاك

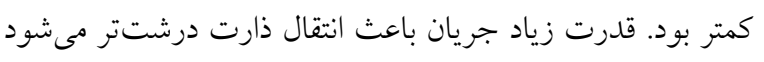

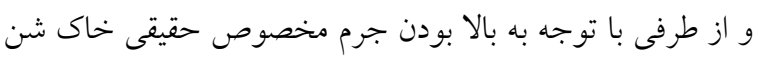



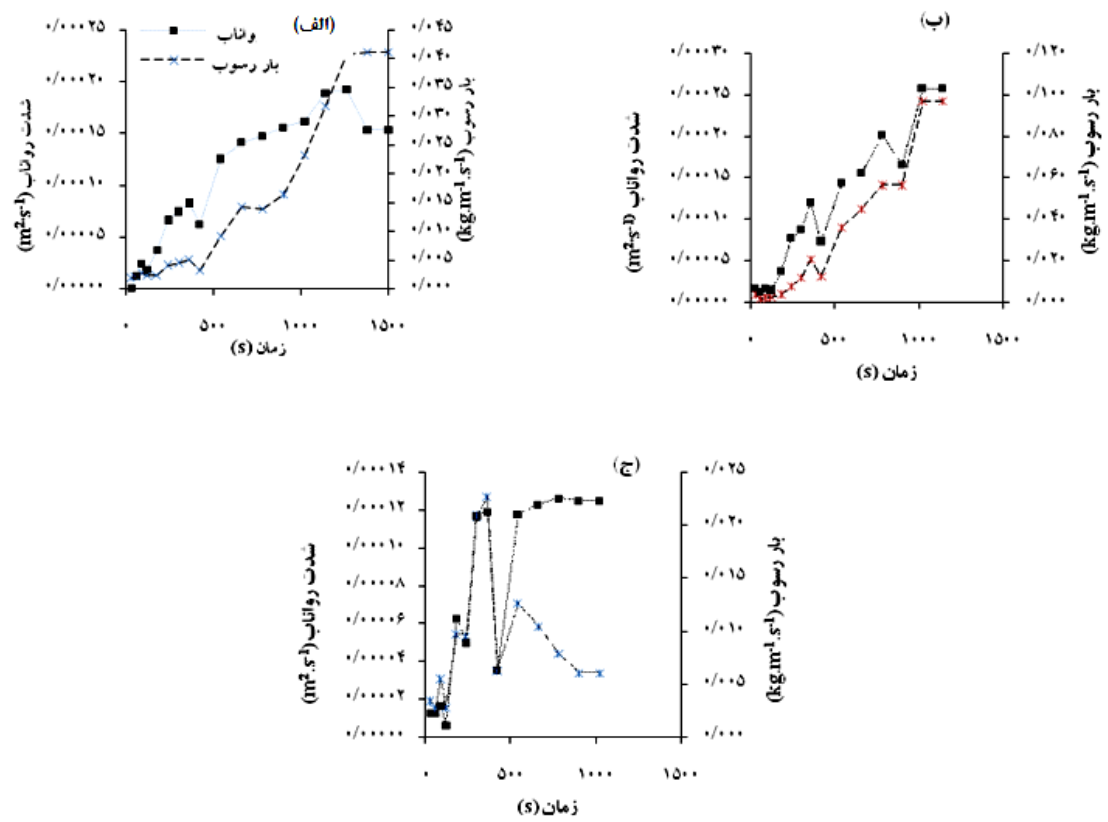

شكل r. تغييرات زمانى بار رسوب و دبى در واحد عرض جريان براى سه خاك بهترتيب:

$$
\text { الف) لوم، ب) شن لومى و ج) لوم رس در واحدى عرض جريان يرى }
$$

تمام خاكدانههاى سطح بـر اثـر ضـربه قطـرات بـاران متلاشسى

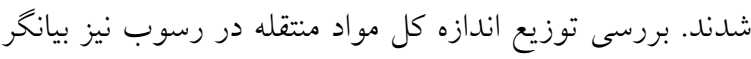
اين موضوع بود كه رسوب فاقد هر كونه ذره ثانويسه (خاكدانسه)

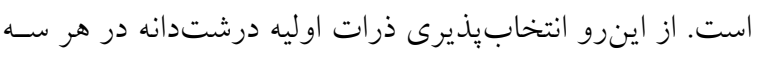

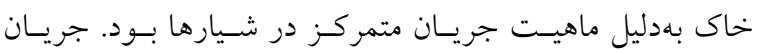

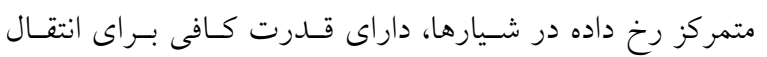

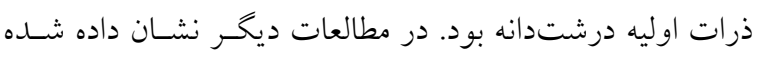

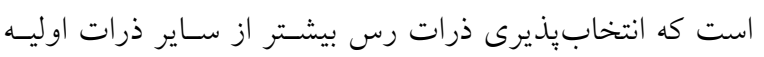

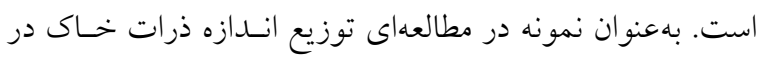

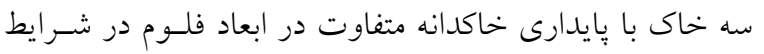

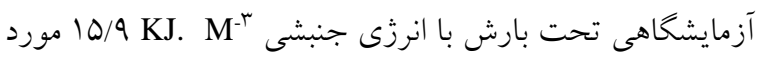

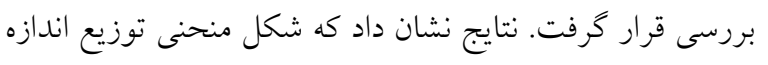

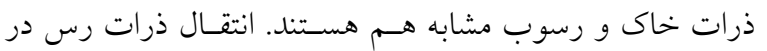
خاكهاى داراى خاكدانه نايايدار بيشتر از خاكهاى با ساختمان

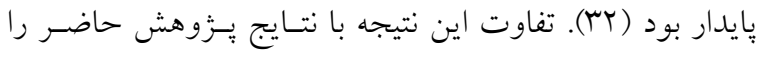

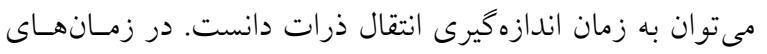

رسوب بهطور ناگهانى كاهش مسىيابــ. در خـاك لـوم شسنى كـه

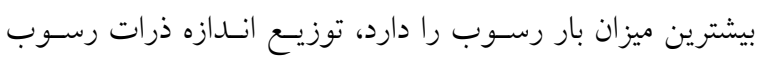

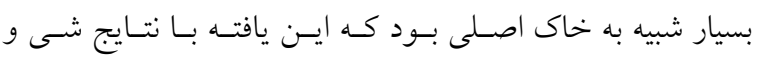
همكاران همسو است (T9). نسبت اندازه ذرات خاك فرسـايش يافتـه بــه انـدازه همـان ذرات در خاك اصلى بيانكر اجـزاى فرسايشى و انتـــال يافتـهـ

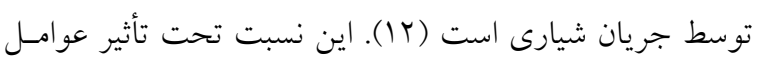

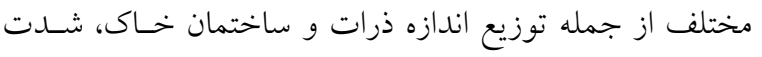

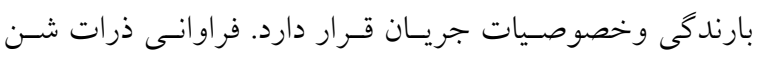

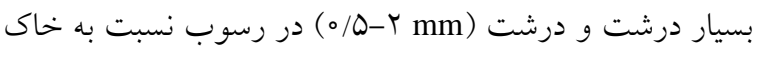

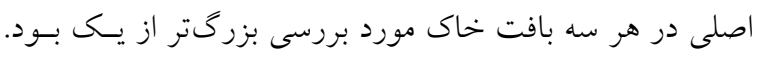

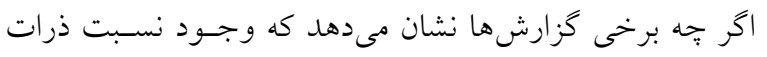

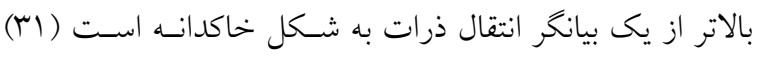
ليكن در خاكهاى مورد بررسى، تشكيل خاكدانه و بايدارى آنها

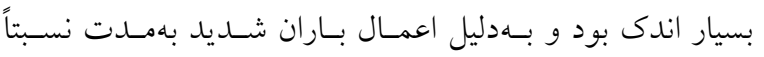
طولانى (90 ميلى متر بر ساعت بهمدت بيش از مبار دقيقه)، عملاً 


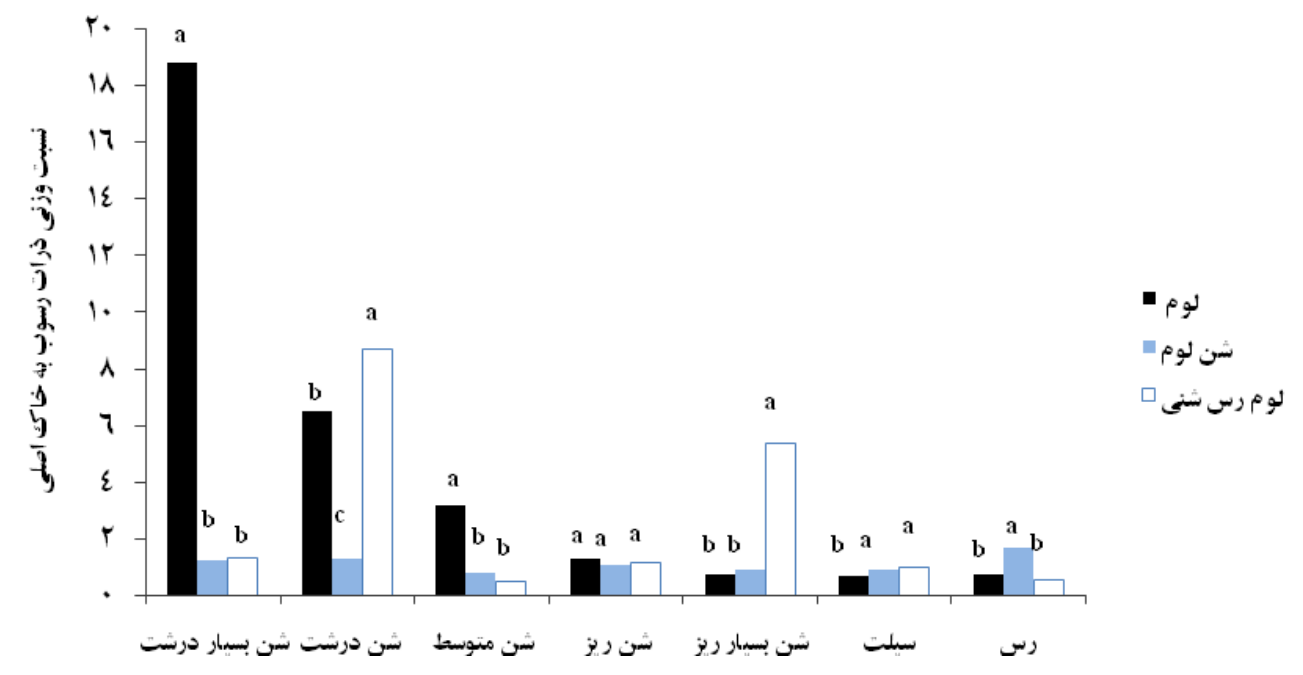

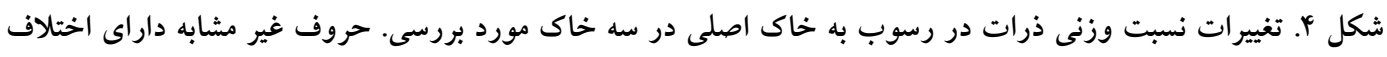
معنى دار در سطح احتمال ينج درصد هستند.

هر سه خاك در محدوده ذرات درشت، بزرگتــ از يـك اسـت

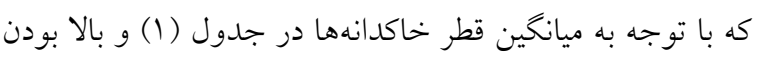

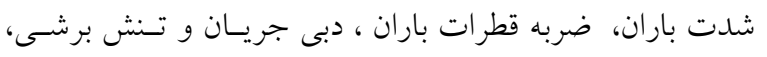

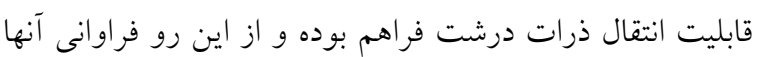
در رسوب بيشتر از خاك اصلى بوده است، قابل توجيـه اسـت.

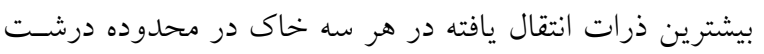

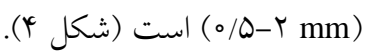

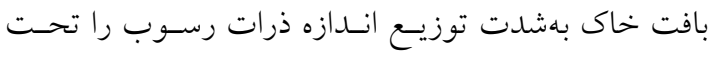

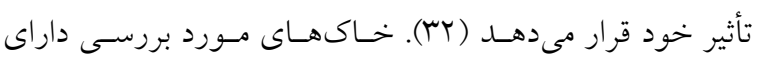

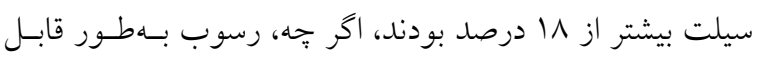
توجهى متشكل از ذرات سيلت نبود. بررسى قطر ميانسه ذرات

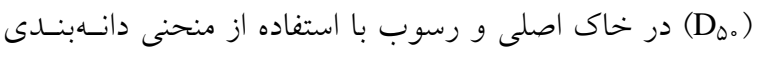

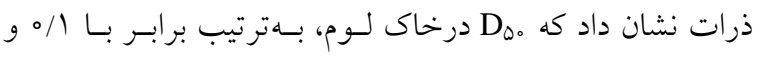

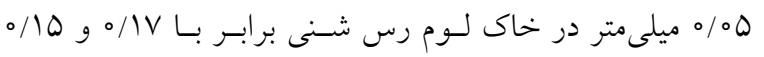

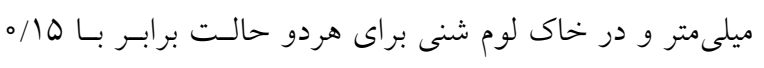

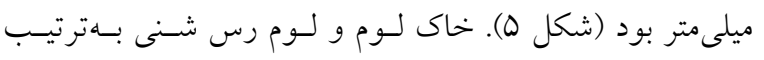

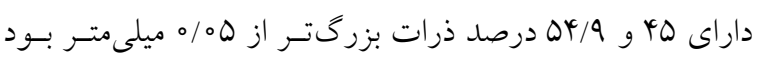

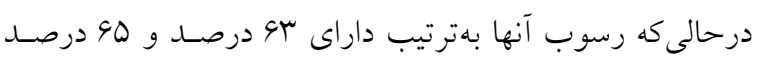

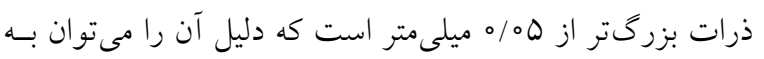

اوليه انتقال، اغلب ذرات ريزدانه منتقل مىشوند و در زمانهـاى

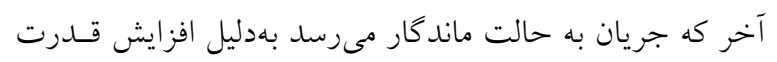

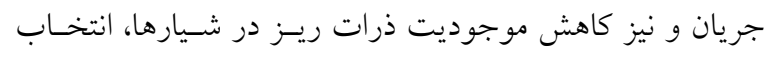
يذيرى ذرات درشت دانه افزايش يبدا مى كند. جريان شيارى بهدليل تنش برشى بالاتر، تـوان انتقـال ذرات دردات

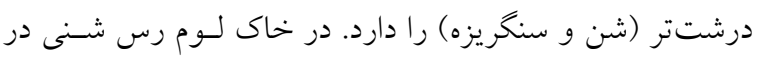

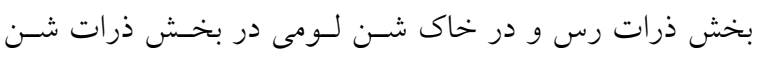

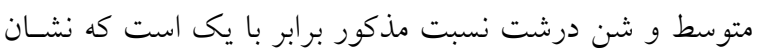

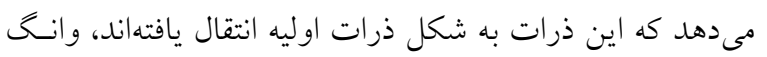

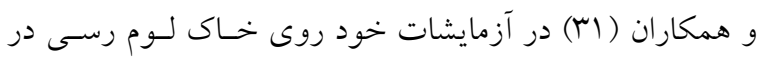
بار انهاى با انرزى جنبشى مختلف، به اين نتيجه رسيدند كـه در

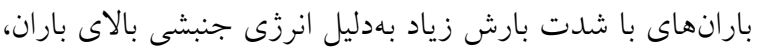

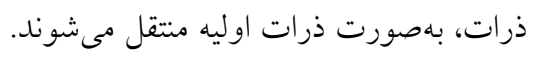

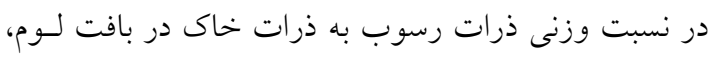

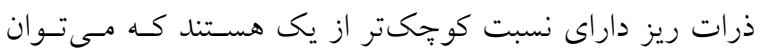

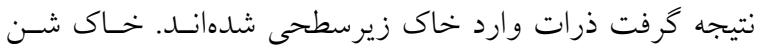
لومى كه حاوى كمترين مقدار رس بود در رسوب آن، در تمـام

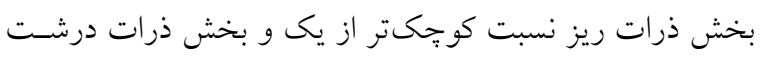

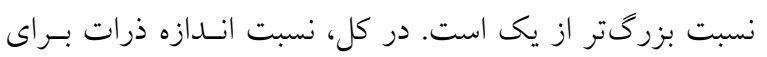




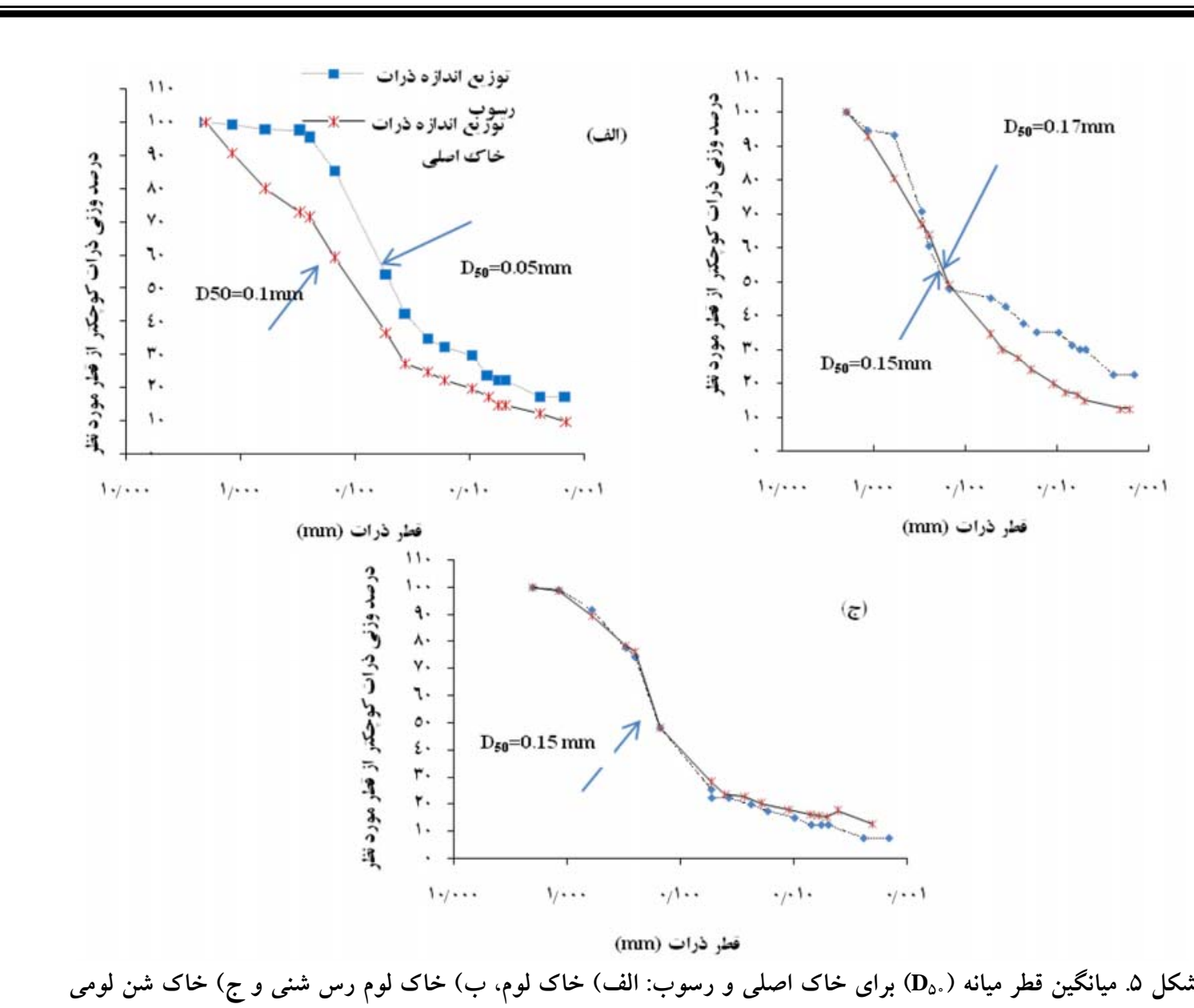

فرسايش شيارى در سه خاى با بافت مختلف با استفاده از باران شبيهسازى شده مورد مطالعه قرار كرفـت. نتـايج نشـان داد كـهـ انتخابِذيرى ذرات تحت تأثير توزيع اندازه ذرات و سـاختمان خاى و خصوصيات جريان قرار دارد. در شـرايطى كـه جريـان شيارى به حالت ماندكار مىرسد، تفاوت اساسى بين خاكها از نظر توليد رواناب و بار رسوب وجود دارد بهطورى كه در خاى

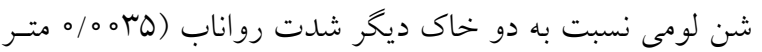
مربع بر ثانيه ) و بار رسـوب (1/ه كيلـو گرم بـر متـر ثانيسه) بـهـ

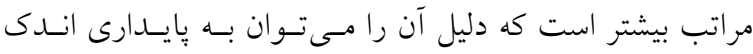
خاكدانههاى آن نسبت به دو خـاك ديخـر نسـبت داد. فراوانسى ذرات شن بسيار درشتت و درشست (r mm-ه/ه) در رسـوب نسبت به خاى اصـلى در هـر سـه بافـت خـاك مـورد بررسىى بزرگتر از يك بود كه دليل آن مىتواند بـهدليل وجـود قـدرت
فرسايش خاك بهصورت ذرات اوليه نسـبت داد. در خهـاك لـوم شنى ذرات بزرگتر از هـ/ ميلىمتر در خاك اصلى و رسـوب يكسان است كه دليل آن يايدارى اندك خاكدانهها در اين خـاك نسبت به دو خاك ديخر است. توزيع اندازه ذرات رسوب لوم و لومرسشنى داراى ذارت ريز نسبتاً بيشترى هستند. توزيع اندازه ذرات به نوبه خود به فرايند غالب فرسـايش وابسـته اسـت. در فرسايش شيارى ذرات درشت اوليه و خاكدانههايى كه مىتوانند سريع تهنشين شوند، توسط جريان شيارى مىتوانند حمل شوند (Y). توزيع اندازه رسوب در اين آزمايش بهشــات تحـت تـأثير

$$
\text { بافت خاك است (شكل ه). }
$$

$$
\text { نتيجه كيرى }
$$

فر ايندهاى فرسايش و انتخابِيذيرى ذرات خاى تحــت فراينــ 


$$
\begin{aligned}
& \text { جريان زياد و ماهيت فرسـايش شـيارى باشـد. از سـوى ديخـر توزيع اندازه كل مواد متتقله در رسوب نيز بيانكر ايسن موضسوع }
\end{aligned}
$$

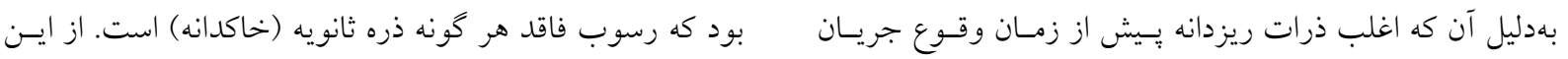

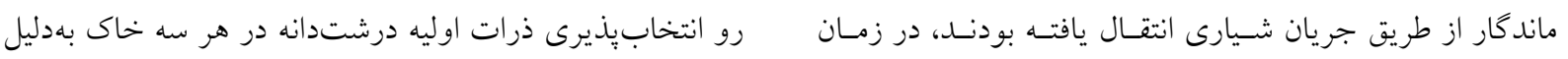

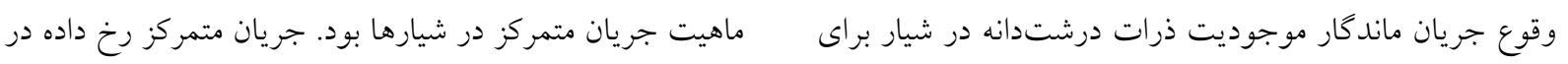

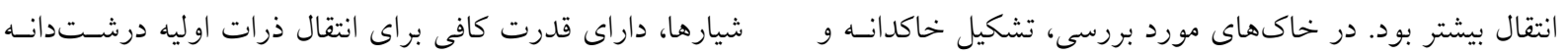

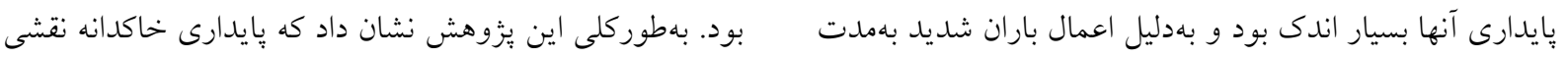

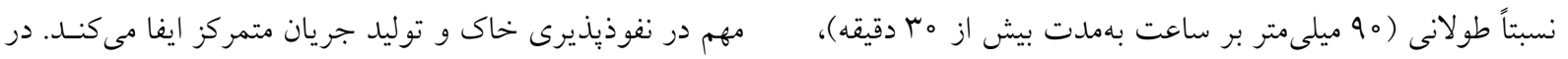

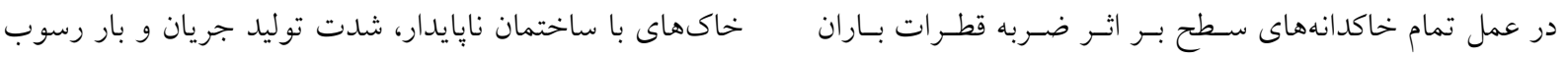

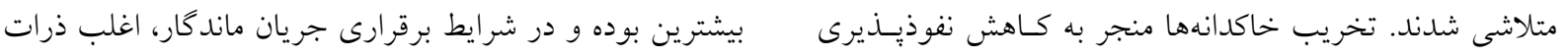

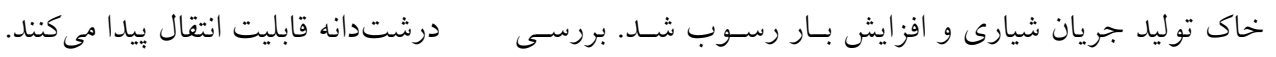

\section{منابع مورد استفاده}

1. Asadi, H. 2005. The study of the processes and basic theories of soil erosion process models. PhD. Thesis, University of Tehran.

2. Asadi, H., A. Moussavi, H. Ghadiri and C. W. Rose. 2011. Flow-driven soil erosion processes and the size selectivity of sediment. Journal of Hydrology 406: 73-81.

3. Asadi, H., H. Ghadiri, C. W. Rose and H. Rouhipour. 2007a. Interrill soil erosion processes and their interaction on low slopes. Earth Surface Processes Landforms 32: 711-724.

4. Asadi, H., H. Ghadiri, C. W. Rose, B. Yu and J. Hussein. 2007b. An investigation of flow-driven soil erosion processes at low streampowers. Journal of Hydrology 342: 134-142.

5. Drees, L., L. Wilding, P. Owens, B. Wu, H. Perotto and H. Sierra. 2003. Steepland resources: Characteristics, stability and micromorphology. Catena 54: 619-636.

6. Farmer, E. E. 1973. Relative detachability of soil particles by simulated rainfall. Soil Science Society American Journal 37: 629-633.

7. Foster, G. R., R. A. Young and W. H. Neibling. 1985. Sediment composition for nonpoint source pollution analyses. American Society of Agricultural Engineers 28: 133-139.

8. Gumiere, S. J., Y. Le Bissonnais and D. Raclot. 2009. Soil resistance to interrill erosion: Model parameterization and sensitivity. Catena 77: 274-284.

9. He, J., X. Li, L. Jia, H. Gong and Q. Cai. 2014. Experimental study of rill evolution processes and relationships between runoff and erosion on clay loam and loess. Soil Science Society American Journal 78: 1716-1725.

10. Kemper, W. D. and R. C. Rosenau. 1986. Aggregate Stability and Size Distribution. In Methods of Soil Analysis, Part I. Physical and Mineralogical Methods (2 ${ }^{\text {nd }}$ Edition) Agronomy Monography, No. 9. Madison, Wisconsin.

11. Klute, A. 1996. Methods of Soil Analysis, Part I: physical and Mineralogical Methods. SSSA Book Series No.5.Soil Science Society of American Madison, Wisconsin.

12. Le Bissonnais, Y. 1996. Aggregate stability and assessment of soil crust ability and erodibility: I. Theory and methodology. European Journal of Soil Science 47: 425-437.

13. Martínez-Mena, M., V. Castillo and J. Albaladejo. 2002. Relations between interrill erosion processes and sediment particle size distribution in a semiarid Mediterranean area of SE of Spain. Geomorphology 45: 261- 275.

14. Meyer, L. D., D. E. Line and W. C. Harmon. 1992. Size characteristics of sediment from agricultural soils. Journal Soil Water Conservation 47: 107-111.

15. Miller, W. P. and M. K. Baharuddin. 1987. Particle size of interrill-eroded sediments from highly weathered soils. Soil Science Society American Journal 51: 1610-1615

16. Misra, R. K. and C. W. Rose. 1996. Application and sensitivity analysis of process-based erosion model GUEST. European Journal of Soil Science 47: 593-604.

17. Mitchell, J. K., S. Mostaghimi and M. Pound. 1983. Primary particle and aggregate size distribution of eroded soil from sequenced rainfall events. American Society of Agricultural Engineers 26: 1773-1777.

18. Nearing, M. A., S. C. Parker, J. M. Bradford and W. J. Elliot. 1991. Tensile strength of thirty-three saturated 
انتخابيذيرى ذرات رسوب در اثر فرسايش شيارى در خاكهاى با بافت مختلف

repacked soils. Soil Science Society American Journal 55: 1546-1551.

19. Pansu, M. and J. Gautheyrou.2006. Handbook of Soil Analysis: Mineralogical, Organic and Inorganic Methods. Springer Science and Business Media.43: 993.

20. Refahi, H. GH. 2006. Soil Erosion by Water and Conservation. Tehran University. Tehran.

21. Regmi, R. K., K. Jung, H. Nakagawa, J. Kang and G. Lee. 2014. Sediment erosion and transport experiments in laboratory using artificial rainfall simulator. Journal of the Korean Geoenvironmental Society 15(4): 13-27.

22. Rhoades, J. D. 1996. Salinity: Electrical conductivity and total dissolved solids, pp: 417-436. Methods of Soil Analysis. Chemical Methods. ASA/SSSA. Madison, Wisconsin, USA.

23. Rienzi, E. A., J. F. Fox, J. H. Grove and C. J. Matocha. 2013. Interrill erosion in soils with different land uses: The kinetic energy wetting effect on temporal particle size distribution. Catena 107: 130-138.

24. Rostami, Y. 2012. Relationship between intensity, duration and kinetic energy of rain using rain simulator in Zanjan province. MSc. Thesis, Zanjan University.

25. Rowell, D. I. 1994. Methods and Application. Longman Group. Harlow.

26. Sadeghi, H. R., M. Kyanihargalani and H. Asadi. 2016. Splash particle size distribution along the experimental flume under different rainfall intensities and slopes. Iranian Journal of Soil and Water Research 47(4): 657-664.

27. Shapiro, S. S. and M. B. Wilk. 1965. An analysis of variance test for normality (complete samples). Biometrika 52(3-4): 591-611.

28. Schiettecatte, W., D. Gabriels, W. M. Cornelis and G. Hofman. 2008. Enrichment of organic carbon in sediment transport by interrill and rill erosion processes. Soil Science Society American Journal 72: 50-55.

29. Shi, Z. H., N. F. Fang, F. Z. Wu, L. Wang, B. J. Yue and G. L. Wu. 2012. Soil erosion processes and sediment sorting associated with transport mechanisms on steep slopes. Journal of Hydrology 454-455: 123- 130.

30. Wang, L., Z. H. Shi, J. Wang, N. F. Fang, G. L. Wu and H. Y. Zhang. 2014. Rainfall kinetic energy controlling erosion processes and sediment sorting on steep hillslopes: A case study of clay loam soil from the Loess Plateau, China. Journal of Hydrology 512: 168-176.

31. Wang, L., Z. H. Shi. 2016. Size selectivity of eroded sediment associated with soil texture on steep slopes. Soil Science Society of American Journal 79: 917-929.

32. Warrington, D., A. Mamedov, A. Bhardwaj and G. Levy. 2009. Primary particle size distribution of eroded material affected by degree of aggregate slaking and seal development. European Journal of Soil Science 60: 84-93.

33. Young, R. A. 1980. Characteristics of eroded sediment. American Society of Agricultural Engineers 23: 1139-1142.

34. Zhang, X. C., Z. B. Li and W. F. Ding. 2005. Validation of WEPP sediment feedback relationships using spatially distributed rill erosion data. Soil Science Society of America Journal 69: 1440-1447. 


\title{
Selectivity of Particles through Rill Erosion in Different Soil Textures
}

\author{
N. Sadeghian* and A. Vaezi ${ }^{1}$
}

(Received: June 22-2017 ; Accepted: October 11-2017)

\begin{abstract}
Sediment selectivity during transport may provide basic information for evaluating on-site and off-site impacts of the soil erosion. Limited information is, however, available on the selectivity of sediments in rill erosion, particularly in the rainfed furrows. Toward this, the sediment selectivity was investigated in three soil textures (loam, loamy sand sand clay loam) under $10 \%$ slope using $90 \mathrm{~mm} . \mathrm{h}-1$ rainfall intensity for $40 \mathrm{~min}$. Soil samples were passed from a $10 \mathrm{~mm}$ sieve and packed in to the erosion flume with $0.4 \mathrm{~m} \times 4 \mathrm{~m}$ in dimensions. Particles size distribution (PSD) was determined in the sediments (PSDs) and compared with the original soil PSD (PSDo). The proportion of PSDs and PSDo was stated as PSDs/PSDo to show the selectivity of soil particles by rill erosion. Based on the results, all three soils appeared as the coarse particles (coarse sand and very coarse sand) in sediments with the PSDs/PSDo>1, indicating the higher selectivity of these particles by rill erosion. Loamy sand was the most susceptible soil to rill erosion among the studied soils, which generated a higher runoff $\left(0.0035 \mathrm{~m}^{2} . \mathrm{s}^{-1}\right)$ and sediment load $(0.1 \mathrm{~kg} . \mathrm{m}-1 . \mathrm{s}-1)$ during rainfall. The PSDs of this soil were similar to those of the original soil PSD. This study revealed that the stability of aggregates could be regarded as the major soil factor controlling rill erosion rate and the sediment selectivity in the semi-arid soils. With an increase in the water-stable aggregates, soil infiltration rate and as a consequence, shear stress of flow could be decreased in the rills.
\end{abstract}

Keywords: Size aggregate; Bed load; Particle size distribution; Stream power; Rolling

1. Department of Soil Science, Faculty of Agriculture, University of Zanjan, Zanjan, Iran.

*: Corresponding Author, Email: nasrin.sadeghian@znu.ac.ir 